\title{
A Study on Establishing the Cooperative Confidence of Chinese Cross-Strait Industry Standard: Taking the Standard Cooperation of LED as an Example
}

\author{
Shaotang $\mathrm{Wu}^{1}$, Wenting Xie ${ }^{2, *}$ \\ ${ }^{1}$ Research Center for China Industry-University-Research Institution Collaborative of Wuhan University, Wuhan, 430072 \\ ${ }^{2}$ Economics and Management Department, Wuhan University, Wuhan, 430072, Hubei, China \\ *Corresponding Author: 278444184@qq.com
}

Copyright $@ 2014$ Horizon Research Publishing All rights reserved

\begin{abstract}
With case study, this paper discusses the establishment and the driving force of the cooperative confidence of cross-strait LED standard. The study shows: there is phased establishment of the cooperative confidence of cross-strait LED standard, including making communication, reaching consensus and establishing confidence. Each stage has different driving forces which are rational economic factor, social factor and sense of national mission; rational economic factor involves in resource dependence, transaction cost and technology development; social factor includes mimetic, coercive, normative forces. Then the cooperative confidence of LED standard has been achieved through the consensus, landing on and leading to the sense of national mission. The establishment of cooperative confidence of cross-strait LED standard is a combination of many factors' effects. These results not only enrich the theory of the establishment reasons of the cross-strait industry, but also provide a new perspective for the establishment of cooperative confidence of cross-strait industry standard.
\end{abstract}

\section{Keywords Cross-Strait Industry Standardizing Cooperation, Cooperative Confidence, LED Industry}

\section{Introduction}

Generally speaking, the risks of cooperation can be divided into relational risks and performance risks. Relational risks refer to the possibility that partners may violate the spirit of cooperation, such as opportunistic behavior and free-riding. Performance risks refer to the possibility of failing to achieve anticipated outcome even if the cooperative relationship is satisfied and relational risks are pretty low. The driving factors of these two risks are different. Relational risks result from the interaction between partners while performance risks are the result of the interaction between organization and environment ${ }^{[1]}$. Over the past twenty years, scholars paid particular attention to relational risks and formed two main research frames: one is based on Transaction Cost Theory and tries to discuss opportunism in cooperative risks while the other, based on Network Theory, puts emphasis on trust in cooperative risks. Though there are numerous members of studies on these two frames, some scholars indicated that it was easy for the discussion of opportunism and trust to fall into the moral myth, which simplifies the entire shaping power of cooperation conditions and external environment on behavior. That means whether the opportunistic behavior occurs sometimes depends on the degree of the honesty of partners, but more depends on the fact that partners' social network, economic or legal norms prohibit them from taking opportunistic behavior or if this relationship is worth to maintain ${ }^{[5]}$. Under this condition, trust is no longer the factor that can eliminate cooperative risks. Meanwhile, opportunistic behavior could not be identified specifically, which means control force from binding contrast could not guarantee the effective operation of cooperation. What's more important is that improper control is likely to weaken trust because one will be less likely to cooperate or trust once feeling partner's willing to dominate himself. Therefore, Hsiung et al. put forward a new concept with management effectiveness, "confidence", in order to explain how to safeguard cooperation. They believed that proper selection and management could generate considerably cooperative confidence ${ }^{[4]}$. Furthermore, management intervention, which means distrust, could also enhance the understanding of partners and increase the confidence of cooperation.

Nowadays, the core of international competition has gradually evolved into the fight for patents and standards; the establishing standard is also the formation of core competitiveness. The principle of Wintel (Windows+Intel) in personal computer field enables Microsoft and Intel to lead the international developing trend of PC industry, which makes following nations have to pay numerous amount of patent fee when they are trying to involve in global production and innovative network ${ }^{[7]}$. Standard is no 
longer just a judgment criterion of production technology, but also a competing form with higher level and more significant influence in international market. With the advance of cross-strait industry cooperation, Chinese LED industry cooperation has gradually become a crucial topic. Besides technology cooperation, standardizing cooperation becomes an important content and sally port of cross-strait LED industry cooperation. Cross-strait LED industry organizations have created a promising situation, under which they achieved unanimous goals of LED industry standardizing cooperation and formed benign interaction so as to seek a place of the lightning system in the third generation. The establishment of cooperative confidence and a crucial step towards cross-strait LED industry standardizing cooperation made significant sense for cross-strait LED industry and the creation of national LED brands. Therefore, taking Chinese cross-strait LED industry standardizing cooperation as an example with case study, this paper discusses the establishing process and mechanism of the cooperative confidence of cross-strait LED standard and aims to build a theoretical framework for the establishing mechanism of the cooperative confidence of cross-strait industry standard.

\section{Literature Review}

\subsection{Standardizing Cooperation}

Taking technology standard as ligament, technology standardizing cooperation is a kind of strategic cooperation relationship which aims to achieve mutually cooperative $R \& D$ and generalize technology standard ${ }^{[8]}$. In advanced technology enterprise cluster, the relationship of technology standardizing cooperation is stable. Competition for standard determines the rise and decline of enterprises even the whole industry, and gives rise to winner-take-all ${ }^{[9]}$. Through technology standardizing cooperation, enterprises can improve anticipated market process, promote the adjustment of market competitive structure, boost the technological evolution of the product market, eliminate potential competitive standard and further expand influence in the formal standardization process ${ }^{[10]}$.

From the perspective of industry standard connotation, some scholars emphasized the development and change of cross-strait industry standardizing cooperation and proposed that there should be new connotation, new thinking and new cooperation pattern during the process from dialogue to actual cooperation ${ }^{[11]}$. In addition, other scholars discussed the strategic selection of standard competition and cooperation. They found compatibility could bring into standard locking benefit and self-reinforcing effect, which will further led to "winner-take-all"; franchise agreement could not only augment the number of enterprises applying its technology in production and draw competitors to its side, but also persuade other enterprises to join in this franchise agreement; strategic alliance contributed to the initial sale volume of technology and increased the likelihood of developing into industry standard or higher-leveled standard ${ }^{[12]}$. Hence, it makes great importance for emerging industries in weak market to implement industry standardizing cooperation. Besides that, $\mathrm{MAO}$ et al. indicated that there was an inseparable relation between the proximity among organizations and technology standardizing cooperation network while geographical proximity, technological proximity and cognitive proximity have a real impact of different degrees on the performance of technology standardizing cooperation in distinct ways. On the whole, the prospective of proximity among organizations, including geographical proximity, technological proximity and cognitive proximity, is more suitable to explain cross-strait industry standardizing cooperation.

Table 1. The type and definition of proximity among organizations

\begin{tabular}{ccc}
\hline Type & Definition & Source \\
\hline Geographical Proximity & $\begin{array}{c}\text { The location where organizations } \\
\text { are within a certain spatial range } \\
\text { The comparison between } \\
\text { Technology (knowledge) stock } \\
\text { organizations owned } \\
\text { The difference of institutional } \\
\text { environment between cooperative } \\
\text { partners }\end{array}$ & Boschma(2005); Knoben \& Oerlemans(2006); MAO et al.(2012) \\
Institutional Proximity & Knoben \& Oerlemans(2006); MAO et al.(2012) \\
Cognitive Proximity & $\begin{array}{c}\text { The degree of agreement on } \\
\text { cooperation basis and prospect } \\
\text { The actual distance affected by } \\
\text { mobility }\end{array}$ & North(1993); Boschma(2005); MAO et al.(2012) \\
Functional Proximity & $\begin{array}{c}\text { The affinity and similarity of } \\
\text { cooperative partners }\end{array}$ & Jerker \& Ola(2007) \\
Correlated Proximity & Jerker \& Ola(2007)
\end{tabular}


Table 2. The comparison of trust and confidence

\begin{tabular}{|c|c|}
\hline Trust & Confidence \\
\hline $\begin{array}{l}\text { Regarding the speculation of partner's inner } \\
\text { intention; the production of trust emphasizes } \\
\text { some individual characteristics like morality }\end{array}$ & $\begin{array}{l}\text { Emphasizing the anticipation of partner's positive actions rather than } \\
\text { negative actions; the production of confidence is related to individual } \\
\text { characteristics, interaction and surrounding circumstance }\end{array}$ \\
\hline $\begin{array}{l}\text { The more trust is put on partner, the more } \\
\text { vulnerable one's own side is to damage }\end{array}$ & $\begin{array}{c}\text { The more confidence is put on partner, the less vulnerable one's own side is } \\
\text { to damage }\end{array}$ \\
\hline More trust means less management control & Proper mode and extent of management control can increase confidence \\
\hline
\end{tabular}

Source: Hsiung et al.(2004).

\subsection{The Definition and Source of Cooperative Confidence}

The concept of confidence and trust are highly similar, therefore, some scholars treat them as one thing. However, other scholars suggested that they were distinct to each other some extent. Siegrist believed that confidence was different from trust because "confidence could be obtained through the knowledge or power to anticipate other's action, which results from the power of imposing sanction or familiarity" ${ }^{\text {[14] }}$. Furthermore, Das and Teng insisted that confidence was "to what degree an organization assures that its partner is in pursuit of common benefit instead of taking opportunistic behavior during the process of cooperation." That means confidence in partners is composed of trust and control force ${ }^{[15]}$. What's more, Siegrist et al. held the opinion that trust was related to shared value, while confidence contained some factors regarding institutions and contracts $^{[16]}$. Earle suggested that the source of confidence was more extensive than trust. Specifically, trust was derived from formal or informal sanction, obligation form kinship network, contract and law ${ }^{[17]}$. Hsiung et al. made a conclusion that trust preferred to the speculation of partner's inner intention (like whether partner is moral or not) while confidence stressed the knowledge and control force of specific actions ${ }^{[4]}$. In fact, both sides of cooperation essentially hope to reduce cooperative risks. However, only trust is not enough to provide the whole cooperation guarantee. Consequently, proper management intervention is needed and contradictorily management intervention means distrusting in the general view of trust. Hence, this paper adopts Dos and Teng's opinion of confidence that trust and management control make up cooperative confidence.

Many scholars discussed the source of cooperative confidence and formed following three opinions.

Study in Transaction Cost Theory underlines that cooperation among organizations is motivated by self-interest to design some organizational government mechanism including interest exchange, negotiation and self-protection in order to improve organizational relationship ${ }^{[18]}$. Hence, the construction of an effective organizational government mechanism is conductive to decrease the transaction cost of communicating and negotiation, improving the efficiency of conflict management and maintain the satisfaction of cooperative relationship. In addition, previous scholars of Transaction Cost Theory who treated "efficiency" as start point considered that in the process of building up cooperative confidence, individual organization not only had to acquire complementary assets by learning, but also had to lessen the possibility of opportunism through effective organizational government mechanism so as to maximize the possession of cooperative performance ${ }^{[20]}$. In recent years, research based on Transaction Cost Theory was merged with the opinion of Network Theory and some informal and soft cooperation guarantee mechanism, like relational contract, relational norms, goal congruence and long-term dependence, to attenuate opportunism.

Scholars of Network Theory put forward some sources of confidence and guarantee, putting emphasis on discussing the confidence factors which could be formed from action makers themselves_relationship, knowledge cognition and threat from partners. For example, cultural value may facilitate to establish cognition and confidence between partners ${ }^{[21]}$. The establishment of cooperative confidence is eventually the formation of "win-win" cooperation mode. According to the opinion of Dyer and Nobeoka, "win-win" situation is an exactly necessary condition to strengthen the frequency of interaction, improve the quality and quantity of organizational relationship and even construct a life community ( shared vision and value) ${ }^{[22]}$. Also "win-win" cooperation mode is a cognitive image or a belief regarding cooperative goal including target, mission, value, action, etc. It is hard to make the goal come true and even communication effective if there is a big difference in value of both sides. Reversely, consensus can be helpful for establishing flexible relationship, resolving conflicts and further enhance cooperative confidence.

Institutional Theory insists that the quest for action legitimacy is a key decision basis for organizations to make strategic decision, which can be raised by social imitation and taking actions conforming to the norms of government and professional groups. The universal value and the institutionalization of norms can provide protection for cooperation. In the meantime, social imitation and taking actions which accord with government and professional group norm could enhance legitimacy of organizational actions, which will be helpful to contribute the cooperative confidence. DiMaggio and Powell indicated that though mimetic, coercive and normative had different drivers, they all could render organizational culture, conduct and performance more similar and heighten cooperative confidence $^{[23]}$. Mimetic mainly comes from the responds of 
organization to some uncertain factors, coercive is based on the influence of policy and power and some consideration of legitimacy, and normative has something to do with professionalization ${ }^{[24]}$. Those institutional powers driving organizational cooperation take effect mainly through social network relationship, some influential organizations (like organizations that are large or successful or possess resource) or professional groups.

\section{Research Method}

Longitudinal investigation is a good method to explore what is the establishment of cooperative confidence of cross-strait industry standard and how to establish it. Case study is suitable to observe and study the longitudinal reform among organizations, which means we can dig deeper into a case with different time points and retrospect the related events in chronological order so that we can easily make "how to establish it" clear. This paper taking LED industry as a study object for the following three reasons: firstly, cross-strait citizens have same origin and cross-strait industries have not only geographical proximity and technological proximity but also institutional proximity and cognitive proximity. That means we have abundant theories to investigate the establishment of cooperative confidence of cross-strait LED industry. Subsequently, the cooperation of cross-strait LED industry, especially the standardizing cooperation, has made rapidly and smoothly progress, which can be treated as a typical example. Consequently, the author can take advantage of close relationship with LED industry. The author has been studying in National Semiconductor Lighting Project Research and Development and Industry Alliance (CSA) for half a year and had opportunity to know, observe and discuss problems emerging in the process of LED standardizing cooperation.

There are two kinds of research data in this paper. One is primary data collected by interviewing, direct observation and participatory observing and the other one is secondary data from relevant literature, case record and physical evidence. The author personally has been working in CSA for interview and secondary data of first phase from April 2010 to August 2010. In the second phase of data collection, subsequent tracking was used to perfect data acquired in the first phase. Specifically, three ways were available to get primary data: (1) field research which allows us to carry out direct observation and anticipated observation further and have an in-depth understanding of diverse key events about the standardizing cooperation of cross-strait LED industry; (2) interviewing some main leading members and professional staff at the production line as well as (3) stakeholders in standardizing cooperation of cross-strain LED industry. The above interviews took the form of semi-structure and structure. Further, secondary data can be collected in the following ways: (1) logs of the main leading members in CSA like Secretary-general Ling $\mathrm{Wu}$ and Executive Vice Secretary-general Jun Ruan; (2) diverse unpublished information like brief work reports, e-journals, speeches and meeting documents during the process of the standardizing cooperation of cross-strait LED industry; (3) all papers and new reports published in industry professional magazine or special materials; (4) Chinese semiconductor lighting network, annual reports, yearbooks and other published materials.

\section{The Process of the Establishment of Cooperative Confidence of Cross-Strait LED Industry Standard}

Born in the early 1960s, LED, which is simple-constructed, small, light, energy-efficient, convenient, fairly anti-seismic and can respond rapidly, is a kind of new solid cold light source. After the naissance of incandescent light and fluorescent light, LED launched a great revolution again in lighting industry. LED technology is regarded as one of the most promising strategic emerging industries because of its rapid development, wide application, strong impact on relevant industries and energy-saving potential. In order to take possession of the commanding height of LED industry and dominant it, many countries like Korea, America and Japan one after the other lobbied international organizations to authorize the LED industry standard they set so that they can build technological barriers and keep foreign enterprises out of this industry. As for China, mainland has potential market but could not provide technological support for standard. On the contrary, Taiwan gets mature technology but a narrow market. That means under this circumstance, only when strengthening the standardizing cooperation of cross-strait LED industry can we achieve a "win-win" situation. Referring to the interviews and secondary data, the establishment of cooperative confidence of cross-strait LED industry standard can be divided into three stages: communication (2006-2008), consensus (2009-2010) and establishment of confidence (since 2011).

\subsection{Making Communication (2006-2008)}

The first stage has witnessed a close communication mainly taking the form of extensive communication, standard discussion and considerable visit activities in cross-strait LED industry to open a promising era of cooperation. As early as the third cross-strait information industry technical standard forum in October 2006, cross-strait industrial circles had exchanged views on the establishment of LED technology standard system and the construction of the cross-strait LED term nouns comparison table. In January 2008, a member of CSA Professor Jiangen Pan was invited to give a report on the latest progress of CSA international test standard and the street lamp standard conditions in mainland China and had a lively discussion on the work of LED industry standard with Taiwan LED professionals of all circles. In April of the same year, the proposal that a common standard should be made as early as 
possible was submitted in LED outdoor public lighting technology standard conference, which hoped both sides to admit the LED testing standard. Also in October representatives of Taiwan Bureau of Standards-Metrology and Inspection visited CSA, having an in-depth discussion on promoting the establishment of cross-strait LED industry standard and finally forming a preliminary cooperation intention on some programs including setting standards, certification and testing. With the help of these exchange visits and seminars, the significant importance of promoting the establishment of cross-strait LED industry standard was clear-cut, which laid a solid foundation for further cooperation.

\subsection{Reaching Consensus (2009-2010)}

With the experience of communication, the process of cross-strait LED industry standard stepped into consensus stage. In June 2009, the Director of Ministry of Science and Technology Jichun Feng led a delegation to attend Taiwanese's first cross-strait cooperation and exchanges conference in LED lighting industry. At this conference, both sides of the strait reached six common views, two of which are "the establishment of cross-strait standardization work mechanism, the setting of cross-strait LED industry standards, and the organizational cooperation of cross-strait LED standard" and the construction of cross-strait LED verification platform, carrying out research on detection technology, testing method and checkout equipment, and the achievement of cross-strait LED standardizing cooperation and five specific cooperation intentions. In November 2009, Vice Minister of Industry and Information Technology Qinjian Lou indicated that in the future both sides would make common standard and create prosperity for LED industry when visiting Lite-on Technology Corporation. And then Taiwan Deputy Director of the Energy Bureau of the Ministry of Economic Affairs Yunming Wang responded to this issue that he hoped cross-strait professors can work together for global market, gradually construct a cross-strait common standard and strengthen the exchange of testing technology so as to facilitate the development of cross-strait standard into an international standard. Being driven by top leadership, in February 2010, Xiamen Bureau of City Product Quality Supervision and Inspection and Taiwan Industrial Technology Research Institute signed a contract LED lighting product testing cooperation intent letter, which formally initiated the cooperation of cross-strait LED lighting industry like product testing and laboratory proficiency testing, marking a major march toward cross-strait cooperation of LED industry. In June of the same year, Chinese Semiconductor Research Institute and Taiwan ITRI Electronics and Optoelectronics Research Institute signed an intent letter and decided to jointly carry out some research on the reliability of LED lighting under special climate conditions. It is obvious that a consensus of cross-strait cooperation of LED industry standard has been achieved and some substantial progressed has been made.

\subsection{Establishing Confidence (since 2011)}

After the communication and consensus, the cooperation of cross-strait LED industry stepped into the third stage, the establishment of confidence. The first thing was constructing cooperative organizations of cross-strait LED industry standard. In June 2011, both sides of the strait made a consensus on the construction of a committee of experts. Subsequently, regional standards that both sides agreed with and abided by should be made. In 2011 the standard luminous diode used for street lighting, which absorbed 7 expert opinions of different institutions in Taiwan, made by cross-strait experts jointly was validated by the official in Fujian province. Thirdly, the work of testing and comparing cross-strait LED components and lamps was finished. Fourthly, the common standard of cross-strait LED was proposed. As early as Jun 2011, cross-strait LED industries signed a memorandum to promote LED lighting standardizing cooperation and then signed three intent letters for standardizing cooperation in July, one of which was LED lighting technological specification and common standard. To the beginning of September, two sides of the strait finally released a common standard on the field of LED including common standard terminology table, common standard interpretation of the plate lamp, testing method of accelerating LED devices' lifespan, etc. Since then, the first cross-strait common industry standard text list was finally born after three-year exploration and a least 8 expert technical team meetings. That meant at this point, the cross-strait was no longer in a simple co-opetition relationship with vertical or horizontal division of the industrial chain, but under a "win-win" situation.

\section{The Establishment of Cooperative Confidence of Cross-strait LED Industry Standard}

As previously mentioned, to study the issue of inter-organizational cooperation, there are mainly three kinds of frameworks. The first one is based on Transaction Cost Theory, stressing how to reduce the opportunistic behavior of partners. And it proposes that the cooperation resulting from self-interest motive and transaction cost saving helps to enhance the inter-organizational relationship ${ }^{[18]}$, leading to share the achievement exclusively as much as possible ${ }^{[20]}$. The second one is Network Theory which discusses the factors of forming trust, such as relationship, knowledge, identity, or the threat of your partners ${ }^{[21]}$. In fact, the establishment of cooperative confidence is the formation of the "win-win" cooperation mode. At last, Institutional Theory thinks the quest for action legitimacy is an important decision basis for strategic decisions, and common values and specification of institutionalization can guarantee a deal. The integration of core views of the above three theories forms the establishment mechanism of cooperative confidence of cross-strait LED industry standard (figure 1 
and table 3).

\subsection{The Implementation of Alliance Strategy and the Formation of Cooperation Network}

Proximity refers to that different subjects have common characteristics of "class" or "group" in network, which means a very close distance with something in certain dimensions. In the strategic interaction, proximity can be defined as the closeness between participants ${ }^{[27]}$. The proximity between organizations and the technology standardizing cooperation relationship have mutual effect and develop in coordination. And the proximity between organizations affects the formation of technology standardizing cooperation relations, which changes with the development of cooperation ${ }^{[13]}$. Since both sides of the strait share the same culture, the organizations of cross-strait LED industry have similarity and closeness in the aspects of the standard value orientation and the standard letter symbol, as well as proximity. Benefiting from the proximity between organizations, cross-strait LED industry organizations begin to implement alliance strategy to establish cross-strait LED industry standardizing cooperation network.

\subsubsection{Geographical Proximity and Technology Proximity}

The obviously geographical proximity enables the communication of information, technology, talents and resources smooth and fluent. This proximity also makes it easier to pay attention to the opportunities and challenges from the other side of strait. In addition, the resource dependence of cross-strait LED industry organizations is very obvious. Specifically speaking, Taiwan has advantages in the LED industry upstream, while mainland has good prospect in the application of market. Meanwhile, both sides have a certain right to speak in international standardization organizations, but very weak. That reveals the inherent technology proximity among the LED industry organizations on both sides, which decides the complementarity and compatibility of technology, and directly affects the produce and development of the standardizing cooperation between organizations. Therefore, geographical proximity and technology proximity make cross-strait LED industrial organizations to pay more attention to the interests of the other side. With the enhancement of the identity and dedication of the other side, the cooperation will become more and more easily ${ }^{[29]}$. At this point, it is more likely to set up cross-strait LED industry standardizing cooperation network by adopting alliance strategy.

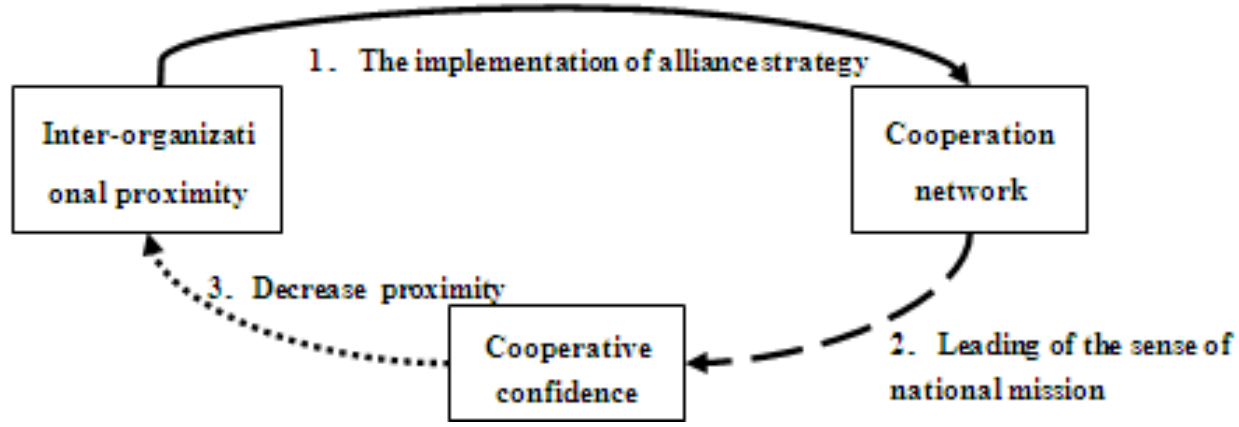

Mechanism 1: The implementation of alliance strategy and the formation of cooperation network

Mechanism 2: Landing and leading of the sense of national mission to establish cooperative confidence

Mechanism 3: Cooperative confidence further reduces inter-organizational proximity

Figure 1. The establishment of cooperative confidence of cross-strait LED industry standar

Table 3. The establishment mechanism of the cooperative confidence of the cross-strait industry standard

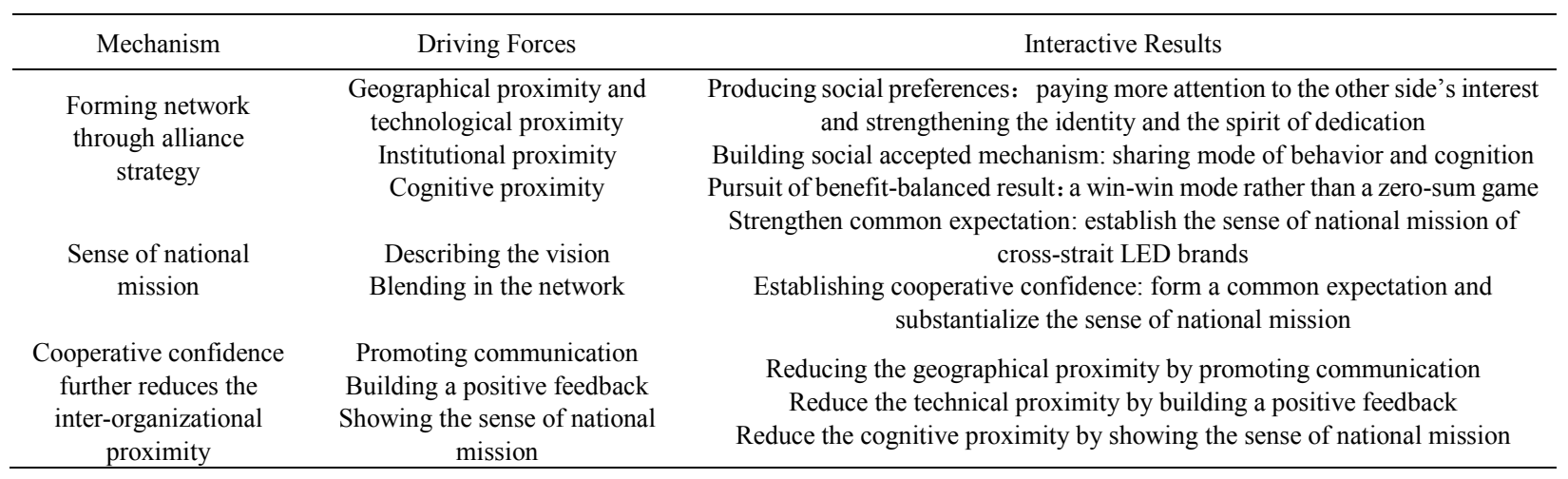




\subsubsection{Institutional Proximity}

Institutional proximity plays a most important role in local innovation system because the local innovation system is on the basis of the collective behavior within the region, and depends on the sharing model of behavioral and cognitive rules $^{[30]}$. The standardizing cooperation of cross-strait LED industry enjoys strong government support and guidance. On one hand, since June 2004 when the mainland started the National Semiconductor Lighting Project, LED industry standardization has become an important work of Science and Technology, the Ministry of National Development and Reform Commission and other ministries. Similarly, the relevant LED patent strategy and standard work has been given high attention by the Taiwan government authorities. On the other hand, cross-strait governments are directly involved in the work of cross-strait LED industry standard. This is a positive signal for cross-strait industries, but also eliminates the political barriers of standardizing cooperation of cross-strait industrial. Thus, the inherent institutional proximity of cross-strait LED industry organizations, to some certain extent, accelerates the construction of social accreditation mechanisms. At this point, the two sides create the cross-strait cooperation network in the LED industry standard network through the implementation of alliance strategy.

\subsubsection{Cognitive Proximity}

The cooperation expectation of the coordination participant is the key factor to achieve mutual benefit equilibrium ${ }^{[29]}$. On the stage of communication, the standard talk of cross-strait LED industry expressed the expectation of building up LED technology standard system immediately, setting up LED term comparison table, making common standard and testing standard. On the stage of consensus, the declaration of formulating LED industry standard together, setting LED test verification platform together, and achieving the mutual recognition of test results also exists. It is the help of coordination and propaganda of the cooperation expectation of cross-strait LED industry standards that cross-strait organizations gradually show cognitive proximity. At this moment, the alliance strategy can help LED industry organizations pursuit mutual benefit equilibrium efficiently.

\subsection{Taking the Sense of National Mission to Build the Confidence of Cooperation}

Actors in standard cooperation network enter into the construction of technical standards with a variety of interest demands. The process of constructing technical standards and the final network, in fact, are the consequences of interaction of different corporations and institutions. Patriotism is defined by some scholars like Balabanis as a promise to be willing to sacrifice oneself for the country, and there is close relationship between brands and national image. During the process, by cross-strait LED industry, from communication about standard cooperation, reaching a consensus and to building confidence, the most important motivation is the sense of national mission to create national brands and achieve the goal of global marketing. From the perspective of core competence, the sense of national mission is mapped as national independent brands, which represent some resources that are valuable, scarce and not easy to be copied. Only through these resources could it be possible for national independent brands to get high paybacks. And only through these resources could the cooperative confidence of cross-straits LED industry standard be stubbornly built.

\subsubsection{Describing the Vision: Strengthen Common Expectation}

If there remains similar culture and frequent communication between cooperators, it will be easier to build stubborn and long-term relationship, which can play a part as a psychological contract ${ }^{[33]}$. As early as June 2010, at the signing ceremony of cross-straits LED industry cooperation, Taiwan side wished that both sides could work together and promote the communication of LED lighting application test validation techniques, so as to achieve common progress and prosperity of both sides under close cooperation, and to create flourishing Greater China. To response to the strong desire of Taiwan LED industry to form national brands, Ling $\mathrm{Wu}$, the Secretary-general of CSA, put forward the target and vision to create world-famous Chinese brands, improved the influence of Chinese products and strived for entering into top three of the world within 3 to 5 years. The industry delegates of both sides reached a consensus about creating cross-straits LED brand, and the sense of national mission had form a common expectation among Chinese LED industry. Many failures of cooperation are due to the lack of common target among cooperators. The consistency of target will help to set the direction of cooperation and construct the rules, as well as to create new value.

\subsubsection{Blending in the Network: Build the Confidence of Cooperation}

On the conference of cross-strait LED industry cooperation and communication in June 2012, the two sides signed two standard cooperation intent letters, and showed the determination that both sides would together strive for the summit point of global LED lighting industry. As the Secretary-general Ling Wu said, the two sides had met an agreement on creating Chinese brands together, and after the signing, "cross-strait LED industry is more like a family". Relying on the technical superiority of Taiwan and the Mainland's ability of industrialization, both sides would together strive for the summit point of global LED lighting industry. The elected representatives of Taiwan were moved by the strong confidence and they presented optimistic attitude when signing the two standard cooperation intent letters in July. They "expect to work together to form brands, something like Zhonghua lighting products". Until the release of LED general standards, the cooperative 
confidence of cross-strait LED industry standard had been constructed. It was exactly the sense of national mission, as well as shared similar culture, regulation and outlook of value between both sides that promoted stronger and stronger cooperative confidence of cross-strait LED industry standard. As Jun Ruan, the Deputy Secretary-general, expected "it's our vision that both sides enter into global markets and together create Chinese brands, and the two sides share the same background", which results in great basis and condition for LED industry cooperation. Similarly, the Chairman of Taiwan Huaju Foudation Ruirong Chen was full of confidence, "the construction of cross-strait industry general standards is the most important element work to promote cross-strait cooperation; steadily carrying forward the process, not only would it be possible to get rid of the destiny to be converging-attacked by South Korea and the West, and open a new era of cross-strait industry cooperation, but the expectation of Chinese brands of both sides would not just be a dream." At this time, it is taking the sense of national mission into cooperation network that guilds the construction of cooperative confidence of cross-strait LED industry standard.

\subsection{Cooperative Confidence Further Reduces the Inter-organizational Proximity}

\subsubsection{Promoting Communication: Reduce Geographical Proximity}

Common standards in the field of cross-strait LED industry fully embody the compatibility of the development characteristics and the target of cross-strait LED industry, and cooperative confidence will make the achievement of our desired objective more predictable. With these compatibility and confidence, geographical proximity can be reduced. For example, through the establishment of technique criterion of Guangzhou Subway demonstration project and Xiamen street lamp demonstration project, along with the memorandum of LED lighting common standardizing cooperation promotion, cross-strait LED industry was assembled and geographical proximity was formed. Furthermore, diverse advice of experts from manufacturing enterprise, research institutes and testing agencies at home and abroad were extensively adopted when the LED industry standard Power light-emitting diode in road lighting by both the China mainland and Taiwan was in approving, researching and soliciting opinions, and we received seven professional advices of several different institutions from Taiwan. Since confidence was built, cooperation like developing LED industry common standard has been more and more and further reduced the geographical proximity directly.

\subsubsection{Building a Positive Feedback: Reduce the Technical Proximity}

The release of cross -strait common standard in the field of LED is the result of cross-strait cooperation in the LED industry. Confidence here represents the strength of cross-strait cooperation in the LED industry and organization, while it will reduce the risks of cooperation and the negative impact brought by the Lock-in Effect commitment, helping the positive feedback to be built. On the one hand, it will do some help to form a kind of forced mechanism in the cross-strait LED industrial organization, encouraging enterprises to consider technological upgrading, improving quality and other issues in advance. Just like an LED lighting company executives once said bluntly: "Companies which do not possess technology and resources may be adversely affected, but for the quality ones, the implementation of common standards will allow them to capture more high-quality non-local customers. And that is good for the development of companies and LED industry itself". On the other hand, it helps incarnating the excellence of complementary advantages, resources dependence and low transaction cost of cross-strait cooperation in the background of fierce LED standard international competition. These positive feedbacks will reduce the technical proximity between the mainland and Taiwan and introduce more common standards.

\subsubsection{Showing the Sense of National Mission: Reduce the Cognitive Proximity}

Cooperation confidence itself has a function of social control that can utilize the organizational value, beliefs or organizational cultures to encourage the desired behavior, while the sense of national mission is the common totem of values and culture norms. This kind of sense stands for patriotism and our lofty goals is an important kind of lubricant and vinculum which promotes the joint of various strengths in cross-strait LED industry, and makes the approval and acception of our common standards more fluent and beneficial, so the cognitive proximity between the mainland and Taiwan can be reduced effectively. Therefore, cooperation confidence shows the sense of national mission, and makes the regional standard that is recognized and abided by the both sides can be passed rapidly and smoothly while the intense international competition is going on, so as to realize the docking and fusion of the cross-strait industry, eliminate the trade and technical barriers, and maintaining the interest of companies from both China mainland and Taiwan.

\section{Conclusions}

Overall, we can conclude the establishment of the cooperative confidence of the cross-strait industry standard. Firstly, forming cooperation network can be formed by implementing alliance strategy and taking the advantage of proximity. Secondly, to build cooperative confidence, national sense of mission can be poured into cooperative network. And lastly, cooperative confidence can further decrease cross-strait cooperative proximity. That means the establishment of cooperative confidence is the combined 
effect of the three factors. this paper makes contributions by taking the view of confidence rather than trust and providing a new angle of view for the study of the standardizing cooperation of cross-strait industry, which not only conforms to the need of practical world, but also integrates the results of transaction cost theory, network theory and institutional theory on cooperative risks. Subsequently, this paper constructs the establishment mechanism of cross-strait industry standard, describing the evolution process from organizational proximity to cooperative network and the establishment of cooperative confidence and enriching the theory of the cooperative confidence of industry standard and the establishment mechanism. Last but not least, this paper finds the positive influence of national mission on the establishment of the cooperative confidence of cross-strait industry standard, which perfects the theory of the cultivation of national mission and cooperative confidence to some extent. As a matter of fact, this point of view is fairly consist with the opinion of Hofstede et al. who found that patriotism and the proud of one's country were listed as one of the six most important items of three groups. Specifically, the group of the mainland China was the one in which patriotism and proud of one's country ranked second ${ }^{[38]}$

The results of this paper offer practical reference to the establishment of cooperative confidence of cross-strait industry standard. Firstly, it points out that it is vital to establish cooperative confidence when undertaking cross-strait industry standardizing cooperation. Secondly, it emphasizes the stages of the establishment of cooperative confidence of cross-strait industry standard and the importance of considering the evolution of organizational proximity, network and cooperative confidence. Thirdly, it indicates that to facilitate the establishment of cooperative confidence of cross-strait industry standard, not only corresponding measures concerning geographical proximity, technological proximity, cognitive proximity and institutional proximity should be taken to decrease the organizational proximity, but also the sense of national mission that is of stability, consistency and value should be stimulated to push the establishment of cooperative confidence of cross-strait industry standard. Certainly, as a case study, this paper's conclusions are not widely applicant and in lack of statistical significance. Drawing on this paper, further research can carry through empirical test by using empirical method and building a statistical method so as to render the conclusion more general.

\section{Acknowledgements}

The research was supported by the Philosophy and Social Sciences Research Program of Ministry of Education (Grant No. 10JZDW003) and the Fundamental Research Funds for the Central Universities.

\section{REFERENCES}

[1] Das, T.K. \& B.S. Teng. Risk types and inter-firm alliance structures, Journal of Management Studies, Vol.33, No.6, 827-843, 1996.

[2] Deeds, D.L. \& C. W. L. Hill. An Examination of Opportunistic Action within Research Alliances: Evidence from the Biotechnology Industry, Journal of Business Venturing, Vol.12, No.2, 141-163, 1999.

[3] Rousseau, D. M., Sitkin, S. B., Burt, R. S., \& Camerer, C. Not So Different after All: A Cross-discipline View of Trust, Academy of Management Review, Vol.23, No.3, 1998.

[4] Hsin-Hua Hsiung, Chwo-Ming Joseph Yu, Dah-Hsian Seetoo. Confidence Building in Partners of Strategic Alliances: An Empirical Study of Taiwanese Firms in the Information Technology Industry, Journal of Management, Vol.21, No.4, 477-497, 2004.

[5] Joshi, A.W. \& R.L.Stump. Determinants of commitment and opportumism: Interating and extending insights from transaction cost analysis and relational exchange theory, Canadian Journal of Aministrative Sciences, Vol.16, No.4, 334-352, 1999.

[6] Chiao, B., Lerner, J. \& Tirole, J. The Rules of Standard-Setting Organizations: An Empirical Analysis, Rand Journal of Economics, Vol.38, 905-930, 2007.

[7] Suttmeier, Richard P. \& Yao, Xiangkui. China's Post WTO Technology Policy: Standards, Software, and the Changing Nature of Techno-Nationalism (Washington, DC: The National Bureau of Asian Research, NBR Special Report, No. 7, May 2004).

[8] Leveque, F. \& Meniere, Y. Technology Standards, Patents and Antitrust, Competition and Regulation in Network Industries, No.9, 29-48, 2008.

[9] Hill, C. W. Establishing a Standard: Competitive Strategy and Technological Standards in Winner-take-all Industries, Academy of Management Executive, No.2, 7-21, 1997.

[10] Kim, S. H. Vertical Structure and Patent Pools, Review of Industrial Organization, Vol.25, 231-250, 2004.

[11] Xin-hong CHEN, Bei-zhang WEN, Pei-ru. YU Strategic Issues of Cross Straits Cooperation in Industrial Standards, Journal of Fujian Normal University(Philosophy and Social Sciences Edition), No.2, 14-18, 2011.

[12] Jinsong TAN and Runhui LOM. TD- SCDMA, and the Str ategic Selection in the Competition of Standards of Telecommunication Industry, Management World, No.6, 71-84, 2006.

[13] Chong-feng MAO, Yan-ping GONG, Qing ZHOU. Study on the Influence between Inter-organizational Proximity and Technological Standardization Collaboration, Scientific Management Research, No.2, 104-108, 2012.

[14] Siegrist M. Trust and Confidence: The Difficulties in Distinguishing the Two Concepts in Research, Risk Analysis, Vol.30, 1022-1024, 2010.

[15] Das, T.K. \& B.S. Teng. Between trust and control: Developing confidence in partner cooperation in alliances, Academy of Management Review, Vol.23, No.3, 491-512, 1998. 
[16] Siegrist M, Earle T.C., \& Gutscher H. Test of a Trust and Confidence Model in the Applied Context of Electromagnetic Field (EMF) Risks, Risk Analysis, Vol.23, 705-716, 2003.

[17] Earle T.C., \& Siegrist M. Morality Information, Performance Information, and the Distinction between Trust and Confidence, Journal of Applied Social Psychology, Vol.36, 383-416, 2006.

[18] Twyman M, Harvey N, \& Harries C. Trust in Motives, Trust in Competence: Separate Factors Determining the Effectiveness of Risk Communication, Judgment and Decision Making, No.3, 111-120, 2008.

[19] Yli-Renko H., Autio E., \& Sapienza H.J. Social capital, knowledge acquisition, and knowledge exploitation in young technology-based firms, Strategic Management Journal, June-July Special Issue, Vol.22, 587-613, 2001.

[20] Besley J.C. Public Engagement and the Impact of Fairness Perceptions on Decision Favorability and Acceptance, Science Communication, Vol.32, 256-280, 2010,.

[21] De Jonge J., van Trijp H., Renes RJ., \& Frewer LJ. Consumer Confidence in the Safety of Food and Newspaper Coverage of Food Safety Issues: A Longitudinal Perspective, Risk Analysis, Vol.30, 125-142, 2010.

[22] Dyer J.H., \& Nobeoka K. Creating and managing a high performance knowledge-sharing network: the Toyota case, Strategic Management Journal, Vol.21, No.3, 45-67, 2000.

[23] DiMaggio, P. J. \& Powell, W.W. The Iron Cage Revisited: Institutional Isomorphism and Collective Rationality in Organizational Fields, American Sociological Review, Vol.48, 147-160, 1983.

[24] Gulati R., \& Gargiulo M. Where do interorganizational networks come from?, American Sociological Review, Vol.104, No.1, 429-493, 1999,

[25] Pettigrew, A.M. Longitudinal Field Research on Change: Theory, \& Practice, Organization Science, No.1, 267-292, 1990.

[26] Fei LI, Hao CHEN, Hongxing CAO and Baolong MA. How should China's Department Stores Carry out the Innovation in Service?, Management World, No.2, 114-127, 2010.

[27] Charness, G., E. Haruvy \& D. Sonsino. Social distance and Reciprocity: An internet Experiment, Journal of Economic Behavior and Organization, Vol.63, 88-103, 2007.
[28] Roderik, Frank \& Koen Frenken. The geographical and institutional proximity of research collaboration, Papers in Regional Science, No.3, 423-443, 2007.

[29] YingLei LI, Jijun XIA. A Review on the Influence of Voluntary Cooperation on Social distance, World Economic Papers, No.2, 89-88, 2009.

[30] Thierry \& Yannick. Innovation and Proximity: Territories as Loci of Collective Learning Processes, European Urban and Regional Studies, No.6, 27-46, 1999.

[31] Balabanis, G., Diamantopoulos, A., Mueller, R.D., \& Melevwar, T.C. The Impact of Nationalism, Patriotism and Internationalism on Consumer Ethnocentric Tendencies, Journal of International Business Studies, Vol.32, No.1, $157-175,2001$

[32] Brouthers, L.E. \& Xu, K. Product Stereotypes, Strategy and Performance Satisfaction: the Case of Chinese Exporters, Journal of International Business Studies, Vol.33, No.4, 657-677, 2002.

[33] Smith, S.J. \& Roehrs, C.J. High-fidelity Simulation: Factors Correlated with Nursing Student Satisfaction and Self-confidence, Nursing Education Perspectives, Vol.30, No.2, 74-78, 2009.

[34] Glenn \& John. Realism Versus Strategic Culture: Competition and Collaboration?, International Studies Review, No.11, 523-551, 2009.

[35] Koriat, A. Subjective Confidence in Perceptual Judgments: A Test of the Self-consistency Model, Journal of Experimental Psychology, Vol.140, 117, 2011.

[36] Kotabe, M., Martin, X., \& Domato, H. Gaining from Vertical Partnerships: Knowledge Transfer, Relationship Duration, and Supplier Performance in the U.S. and Japanese Automotive Industries, Strategic Management Journal, Vol.24, No.4, 2003.

[37] Moorman, C., Zaltman, G., \& Deshpande, R. Relationships between Providers and Users of Market Research: The Dynamics of Trust within and Between Organizations, Journal of Marketing Research, Vol.29, No.3, 1992.

[38] Hofstede, G., Van Deusen, C.A., Mueller, C.B., \& Charles, T.A. The Business Goals Network. What Goals do Business Leaders Pursue? A Study in Fifteen Countries, Journal of Internal Business Studies, Vol.33, 785-803, 2002. 